\title{
Rapid Analysis and Authentication of Meat Products using the MasSpec Pen Technology
}

Abigail N. Gatmaitan, John Q. Lin, Jialing Zhang, and Livia S. Eberlin*

Department of Chemistry, The University of Texas at Austin, Austin, TX, 78712

* to whom correspondence should be addressed: liviase@utexas.edu

\begin{abstract}
Food authenticity and safety are major public concerns due to the increasing number of food fraud cases. Meat fraud is an economically motivated practice of covertly replacing one type of meat with a cheaper alternative, raising health, safety, and ethical concerns for consumers. In this study, we implement the MasSpec Pen technology for rapid and direct meat analysis and authentication. The MasSpec Pen is an easy-
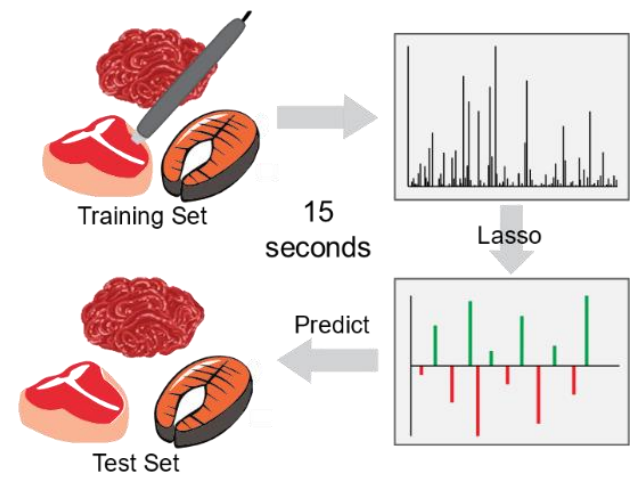
to-use handheld device connected to a mass spectrometer that employs a solvent droplet for gentle chemical analysis of samples. Here, MasSpec Pen analysis was performed directly on several meat types including grain-fed beef, grass-fed beef, venison, cod, halibut, Atlantic salmon, sockeye salmon, and steelhead trout, with a total analysis time of 15 seconds per sample. Statistical models developed with the Lasso method using a training set of samples yielded per-sample accuracies of $95 \%$ for the beef model, $100 \%$ for the beef versus venison model, and $84 \%$ for the multiclass fish model. Metabolic predictors of meat type selected included several metabolites previously described reported in the skeletal muscles of animals, including carnosine, anserine, succinic acid, xanthine and taurine. When testing the models on independent test sets of samples, per-sample accuracies of $100 \%$ were achieved for all models, demonstrating the robustness of our method for unadulterated meat authentication. MasSpec Pen feasibility testing for classifying venison and grass-fed beef samples adulterated with grain-fed beef achieved persample prediction accuracies of $100 \%$ for both classifiers using test sets of samples. Altogether, the results obtained in this study provide compelling evidence that the MasSpec Pen technology is as a promising alternative analytical method for the investigation of meat fraud.
\end{abstract}




\section{Introduction}

Food fraud is an increasing public health and commercial concern for consumers and vendors. Currently, food fraud costs the global food industry between an estimated $\$ 10$ billion and $\$ 15$ billion per year. ${ }^{1-2}$ The 2013 European horse meat scandal, for example, caught international attention of consumers by revealing that meat products labeled as beef contained as high as $80-100 \%$ horse meat. ${ }^{3-4}$ Thus occurrence led many countries to examine their own meat and food fraud policies to advance prevention of this crime..$^{5}$ The most common method for meat fraud is replacement, which involves the complete or partial substitution of a meat product with a less expensive adulterant, such as replacing beef for horse meat. ${ }^{1-2,4,6-7}$ The substitution can be made by replacing the whole meat product, such as a steak or fish fillet, or by incorporating the adulterant into a ground meat product at a certain percentage. ${ }^{1-}$ ${ }^{2,6-8}$ In addition to the economic and criminal effects of this practice, meat fraud also affects consumers with meat allergies or other dietary, religious and cultural restrictions, while also representing an ethical violation of the trust of the costumers.

Physical and molecular evaluation of meat products is routinely performed to verify its authenticity and assure product quality before reaching the costumer. For example, in the United States, meat products from farms are continuously inspected by the United States Department of Agriculture (USDA) Food Safety and Inspection Service (FSIS) for authenticity and quality both before (ante mortem) and after (post-mortem) slaughter. For instance, meat will be inspected ante mortem for disease, illness, injury, identification, etc., and inspected postmortem for incidental or purposeful cross contamination, identification, bacterial growth, etc. Following visual inspection, randomly chosen meat products undergo speciation and hormone tests before reaching the consumer in a FSIS facility to detect the type(s) of meat and hormones present in a product. ${ }^{1}$ Polymerase chain reaction (PCR) and liquid chromatography mass spectrometry (LC-MS) are the most commonly used techniques for meat authentication. In PCR assays, accuracies from $96 \%$ to $100 \%$ are reported for the identification of a variety of meat types. ${ }^{8-12}$ PCR assays require targeted molecular probes for testing of the DNA material extracted from the meat product, and can often take four hours to several days to yield a result. ${ }^{8,10}$ Mass spectrometry methods have been increasingly employed as a faster alternative test for meat speciation. ${ }^{2,8}$ LC-MS techniques are commonly used to identify meat type based on quantitative analysis of lipids and proteins that are characteristic of each meat type. Detection limits below 3\% in terms of partial substitution limits have been reported using LC-MS, in a time frame 
normally ranging from three hours to two days for completion, depending on the sample preparation methods used. ${ }^{13-14}$ LC-MS is also frequently used to identify the nature of the contaminants present in the meat, or food products. ${ }^{2}$, ${ }^{6,15}$ For example, LC-MS has been used to detect adulterants that are added to a meat product for financial gain, such as soybean protein added to beef or chicken in pork meat. ${ }^{2,6,14,16}$ Although LC-MS assays allow faster analysis when compared to PCR, the time required for sample preparation steps and chromatographic separation hinders its use for direct, real-time analysis of food products. ${ }^{8,17}$ Moreover, PCR and LC-MS instrumentation is complex and often done off-site at a FSIS facility, thus requiring time for sampling, transportation to the analysis site, and storage.

Several ambient ionization MS techniques have been explored as methods for direct and on-site food analysis, including analysis of meat products in an effort to expedite and improve accessibility to fraud testing. ${ }^{17-25}$ Liquid extraction surface analysis MS (LESA-MS), for example, has been explored for meat authentication based on proteomic analysis a sample digest from various raw, cooked, and processed meat products, followed by analysis using nanoESI. ${ }^{26-28}$ Using this approach, M. Montowska and coworkers reported a predictive variation of $94.9 \%$ using orthogonal partial least squares discriminant analysis in the identification of cooked horse, pork, turkey, chicken, and beef ( $\mathrm{n}=50)$ using peptide biomarkers. This study also reported partial substitution limits of detection of $10 \%$ for pork, horse, and turkey and $5 \%$ for chicken in beef matrices $(n=50) .{ }^{26}$ Rapid evaporative ionization MS (REIMS) has also been explored for meat authentication. In REMS, a handheld electrocautery device is directly used to thermally ablate the meat sample, leading to the formation of an aerosol that is transported to a mass spectrometer for lipidomic analysis. ${ }^{29-32}$ REIMS was used to analyze a wide range of meat samples, including beef, horse, venison, and various fish species in multiple studies. ${ }^{30-33}$ One of these studies by J. Balog, et al., yielded high prediction accuracies of $100 \%$ for horse and beef and $97 \%$ prediction accuracy at the breed level $(n=20)$ using leaveone-animal-out-cross validation, as well as 5\% detection limit for mixed samples of Wagyu beef and horse meat mixed into venison and grain-fed beef meat, of beef, venison, and horse meat, and of all four meats. ${ }^{34}$

Here, we explore the use of the MasSpec Pen technology as an alternative approach for rapid and direct meat authentication of unadulterated and adulterated meat samples. ${ }^{35-36}$ The MasSpec Pen is a handheld device coupled to a mass spectrometer that enables direct sample analysis based on a gentle liquid-extraction process. Upon contacting the device onto a sample surface and pressing a foot pedal, a syringe pump delivers a discrete solvent droplet to a reservoir at the pen tip, where it is held in contact with the sample for 3 seconds. The solvent 
gently extracts molecules such as small metabolites and lipids from the sample into the droplet, which is then transported through polytetrafluorethylene (PTFE) tubing to the mass spectrometer for analysis. The entire process from contact to analysis is completed in seconds. ${ }^{35}$ Notably, the gentle nature of the liquid-extraction process allows molecular analysis without apparent damage to the sample surface. We have previously shown that the molecular data acquired using the MasSpec Pen in conjunction with statistical modeling via the lasso method allows discrimination of normal and cancerous human tissues with overall accuracies over $96 \% .{ }^{35-36}$ Here, we show that the MasSpec Pen allows effective molecular analysis of various meat samples, enabling meat authentication in seconds.

\section{Materials and Method}

Samples. Meat samples of grain-fed beef $(n=13)$, grass-fed beef $(n=13)$, pork $(n=5)$, chicken $(n=5)$, lamb $(n=5)$, venison $(n=13)$, cod $(n=13)$, halibut $(n=13)$, Atlantic salmon $(n=14)$, sockeye salmon $(n=13)$, and steelhead trout $(\mathrm{n}=13)$ were obtained from local grocery stores (Austin, TX) and stored at $4^{\circ} \mathrm{C}$ until analysis. Each meat sample (or biological replicate) was from a different animal. Only samples that were verified as being regulated by the USDA were purchased. Mixed meat samples containing either grain-fed beef and venison $(n=31)$ or grain-fed and grassfed beef $(n=31)$ were made in the laboratory using pure meat products that were ground together at different ratios $(0,25,50,75$, and $100 \%)$ using a meat grinder. Samples were processed through the grinder at least three times to yield a uniform distribution of each product and were stored at $4^{\circ} \mathrm{C}$ until analysis. Prior to MasSpec Pen analysis, all samples were brought to room temperature and any excess moisture on meat samples was removed with a Kimwipe.

MasSpec Pen Analysis. The MasSpec Pen design and experimental setup have been previously described in detail. ${ }^{35}$ Polydimethylsiloxane pen tips with a $4 \mathrm{~mm}$ reservoir diameter and a solvent droplet volume of $20 \mu \mathrm{L}$ were used for all experiments. Various solvent systems (water, methanol:water blends, and acetonitrile:dimethylformamide (ACN:DMF) blends), extraction times (3, 5 and 10 seconds), and PTFE tubing lengths $(0.5,0.75,1.0$, and $1.5 \mathrm{~m})$ were tested. Between analyses, a wash step was performed where the pen system was flushed with the solvent system. Tubing and pen tips were changed between meat types. For quality control, a background analysis was performed at the beginning and between analyses to monitor and minimize carryover. The 
MasSpec Pen was coupled to a Q Exactive Hybrid Quadrupole-Orbitrap and to a Q Exactive HF Hybrid Quadrupole-Orbitrap mass spectrometer (Thermo Scientific, San Jose, CA) for analysis of the meat samples at ambient conditions. All analyses were conducted in the negative ion mode with a mass range of $m / z$ 50-600 and 140,000 resolving power (at $\mathrm{m} / \mathrm{z}, 200$ ). Eight or nine analytical replicates were acquired for each biological replicates of each meat type, by performing MasSpec Pen analysis of different regions of the meat piece. For each mixed meat sample, three to five analytical replicates were analyzed depending on the size of the sample. Test set samples were analyzed separately two months apart from the training set of samples and treated as an independent sample set. Ions were tentatively identified based on high mass accuracy measurements (mass error $\leq 5 \mathrm{ppm}$ ) and higher energy collision induced dissociation (HCD) tandem MS analyses (Supplemental Figure 3).

Statistical Analysis. Following analysis with the MasSpec Pen, three scans were averaged for each analytical replicate. The resulting mass spectrum was extracted from the XCalibur raw data. The relative standard deviation (RSD) of the method was calculated using the average and standard deviation of ratios of biological ions detected in the mass spectra for each meat type in the optimization study. For further statistical analysis, data were imported into the $\mathrm{R}$ programming language. All mass spectra were normalized according to total ion count. Following normalization, all background peaks and peaks not present in at least $10 \%$ of samples were excluded. Cosine statistical analysis was performed using the las package in R. Principal component analysis (PCA) was performed by centering the preprocessed data to mean zero and computing principal components in R. Lasso was applied to developed classification models using the glmnet package in the $\mathrm{R}$ language. Lasso is a logistic regression technique that selects a sparse set of features, specifically $\mathrm{m} / z$ values, to create a predictive model, or classifier, capable of discriminating between two or more classes, or in this case different meat types. ${ }^{37} \mathrm{~A}$ training set of MasSpec Pen data was used to build each classifier using leave-one-out cross validation (Supplemental Figure 2). The test set of independent samples was used to evaluate the performance of the classification models. Performance of the classification models was measured by recall for each meat type and by an overall accuracy for each classifier.

\section{Results and Discussion}

\section{Optimization of the MasSpec Pen for meat analysis}


We optimized the MasSpec Pen solvent system, extraction time, and tubing length to enable molecular analysis of meat samples. Solvent systems of water, methanol:water blends, and acetonitrile:dimethylformamide (ACN:DMF) were tested by analyzing grain-fed beef, pork, chicken, and lamb and evaluating the diversity of molecular species detected as well as the reproducibility of the mass spectra. Six biological replicates for each meat type and nine analytical replicates per sample were performed. Note that all the solvent systems tested were nondestructive to the meat tissue, thus allowing repeated analyses of the same sampling spot, if desired. Within the solvents tested, pure water and a mixture of $\mathrm{ACN}$ :DMF (1:1) solvents yielded rich mass spectra profiles characterized by a variety of metabolites and fatty acids. For example, the chlorine adduct of hexose $\left(\mathrm{m} / \mathrm{z} 215.031,[\mathrm{M}+\mathrm{Cl}]^{-}\right)$, deprotonated carnosine $(\mathrm{m} / \mathrm{z} 225.098)$, amino acids including deprotonated methylhistidine $(\mathrm{m} / \mathrm{z} 168.076)$ and deprotonated glutamine $(\mathrm{m} / \mathrm{z}, 145.060)$ and fatty acids such as deprotonated FA 18:2 (m/z 279.232) and FA 20:4 $(\mathrm{m} / \mathrm{z} 339.200)$ were observed in the mass spectra obtained with both solvents at high relative abundance. Although complex lipids are commonly observed with the MasSpec Pen in tissue analysis, the $m / z$ range for analysis of meat products was restricted to $\mathrm{m} / \mathrm{z} 600$ to focus on the analysis of the detection of small metabolite species. Generally, we observed that ACN:DMF (1:1) allowed detection of a richer diversity of molecular species, with species such as deprotonated galactitol $(\mathrm{m} / \mathrm{z}$ 181.070), deprotonated taurine $(\mathrm{m} / \mathrm{z}$ 124.006), and deprotonated inosine $(\mathrm{m} / \mathrm{z} 267.073)$ detected using ACN:DMF, but undetected with water. Additionally, ACN:DMF yielded higher reproducibility (RSD of $15 \% \pm$ $4 \%, n=6$ for each meat type) when compared to what achieved with water (RSD of $34 \% \pm 7 \%$ for mass spectra of all meat types, $n=6$ for each meat type) (Supplemental Figure 1). Thus, ACN:DMF (1:1) was used as the solvent system for the remaining experiments performed.

Next, we optimized the MasSpec Pen extraction time by varying the time (3, 5 and 10 seconds) that the pen and the solvent droplet was in contact with grain-fed beef samples. To compare the mass spectra between varying extraction times, a cosine similarity analysis was performed. As previously reported in experiments with human tissues ${ }^{35}$ reproducible mass spectral profiles were obtained for the different extraction times explored, yielding an average cosine value of $0.985 \pm 0.0 .009$. An extraction time of 3 seconds was selected for the analyses to expedite total analysis time per sample. Lastly, different PFTE tubing lengths $(0.5,0.75,1.0$. and $1.5 \mathrm{~m})$ were also tested. The mass spectra obtained of grain-fed beef samples using $0.5,0.75,1.0$. and $1.5 \mathrm{~m}$ tubing lengths, resulted in an average cosine value of $0.97 \pm 0.02$, and shows that the mass spectra profiles are nearly independent of tubing 
length, which also corroborates previous findings ${ }^{35}$. Thus, the shortest tubing length of $0.5 \mathrm{~m}$ was used for all following analyses to conserve PTFE tubing material and expedite analysis time per sample. Using $0.5 \mathrm{~m}$ PFTE tubing length, droplet transport from the pen tip to the mass spectrometer was completed in 2 seconds. At the optimized conditions, each analysis was performed with ACN:DMF (1:1) solvent, 3 seconds of extraction time, 0.5 m PFTE tubing, for a total analysis time of $\sim 15$ seconds per sample, which is faster than PCR and LC-MS, the current gold standard methods., 2,8

\section{Pilot study of MasSpec Pen meat speciation}

We then performed a preliminary study to determine if the molecular profiles obtained with the MasSpec Pen were capable of distinguishing visually distinctive meat types, including grain-fed beef, pork, chicken, and lamb (five biological replicates per meat type, four analytical replicates per sample). As expected, different mass spectral profiles were obtained from the MasSpec Pen analysis of each meat type (Figure 1a). Deprotonated carnosine $(\mathrm{m} / z$ 225.099), for example, was detected in all meat types with high abundances in beef and pork, which was previously detected in various meat types using LC-MS. ${ }^{38-39}$ Deprotonated anserine $(\mathrm{m} / \mathrm{z} 239.115)$ and deprotonated succinic acid $(m / z, 117.018)$ were detected in beef, lamb, and chicken. Furthermore, deprotonated xanthine $(m / z$ 151.025) was detected in chicken and beef at a higher abundance when compared to lamb and pork, while deprotonated taurine $(\mathrm{m} / \mathrm{z}$ 124.006) was detected in relatively high abundance in all meat types. These molecules were previously detected using LC-MS in various meat types. ${ }^{40-41}$ Using PCA, separation between the data obtained from the four meat types evaluated was achieved (Figure 1b), thus confirming that the molecular information obtained using from MasSpec Pen analysis is distinct between meat types.

\section{Developing beef and venison authentication models using the MasSpec Pen.}

We next used the MasSpec Pen to analyze commonly substituted meat products. One set of commonly substituted meat products are grain-fed beef and grass-fed beef, which are the same meat species with different feeding habits. Typically, grass-fed beef is the more expensive of the two, thus grain-fed beef can be mislabeled as grass-fed for a larger profit. ${ }^{42}$ Another set of commonly substituted meat products are grain-fed beef and venison, which is also 
performed for financial gain. For each meat type, ten raw samples were analyzed with at least eight analytical replicates per sample, yielding 254 spectra from the 30 meat samples.

Representative mass spectra are shown in Figure 2a for a sample of grain-fed beef, grass-fed beef, and venison. Qualitative differences in the relative abundances of several metabolic species previously reported in the skeletal muscles of animals can be seen when comparing the mass spectra obtained. For example, deprotonated carnosine ( $\mathrm{m} / \mathrm{z} 225.099)$, previously reported in skeletal muscles of beef and chicken using LC-MS, was detected at a high relative abundance in both beef profiles when compared to venison. ${ }^{38-39}$ Additionally, deprotonated malic acid $(\mathrm{m} / \mathrm{z}$ 133.013) and deprotonated anserine $(\mathrm{m} / \mathrm{z} 239.115)$ are at an increased relative abundance in grain-fed beef when compared to venison and grass-fed beef. Moreover, a higher relative abundances of deprotonated xanthine $(\mathrm{m} / \mathrm{z}$ 151.025) was detected in venison and grain-fed beef, while a lower relative abundances of deprotonated taurine $(\mathrm{m} / \mathrm{z}$ 124.006) in grass-fed beef and venison, both of which have been previously observed in beef and fish meat using LC-MS. ${ }^{40-41}$ Interestingly, a qualitative higher relative abundance of the chlorine adduct of hexose $(\mathrm{m} / z$ 215.032, $\left.[\mathrm{M}+\mathrm{Cl}]^{-}\right)$was detected in grain-fed beef, which could be associated with the diet of grain-fed cattle containing more sugars than the diet of grass-fed cattle. ${ }^{43}$

Using the data collected, we created two two-class classification models, one for grain-fed and grass-fed beef, and one for grain-fed beef and venison using the Lasso method. ${ }^{35,44-45}$ For the beef two-class model, 176 spectra acquired from 20 samples were used as the training set of data using leave-one-out cross validation (LOOCV). A per-sample accuracy of $95 \%$ was achieved (Figure 2b), which is particularly encouraging as the samples are from identical species with the main difference being feeding habits. Notably, within the predictive $\mathrm{m} / \mathrm{z}$, deprotonated malic acid $(\mathrm{m} / \mathrm{z}$ 133.013), deprotonated carnosine $(\mathrm{m} / \mathrm{z} 225.099)$, and the chlorine adduct of hexose $(\mathrm{m} / \mathrm{z} 215.032)$ were selected, which corroborate with the trends in ion relative abundances observed in the mass spectra. For the beef versus venison model, 165 spectra acquired from 20 samples were used as the training set, yield a per-sample accuracy of $100 \%$ (Figure 2c). The predictive $\mathrm{m} / \mathrm{z}$ selected included ions deprotonated xanthine $(\mathrm{m} / \mathrm{z}$ 151.025), deprotonated carnosine $(\mathrm{m} / \mathrm{z} 225.099)$, and deprotonated anserine $(\mathrm{m} / \mathrm{z} 239.115)$. To evaluate the performance of the model for meat authentication setting, a test set of samples were used, as discussed later in the manuscript. 


\section{Developing a fish authentication multiclass model using the MasSpec Pen.}

We then examined the MasSpec Pen's performance for fish identification for a multiclass fish model. Here, we analyzed five common fish products, steelhead trout, sockeye salmon, Atlantic salmon, cod, and halibut. For each meat type, nine samples were analyzed as a training set of samples, with at least eight analytical replicate analyses performed for each sample, yielding 395 spectra from the 45 samples analyzed.

When evaluating the molecular profiles of the raw samples analyzed with the MasSpec Pen, qualitatively district mass spectra profiles were detected for each fish type, as shown in Figure 3a. For example, deprotonated taurine $(m / z, 124.006)$, was detected at varying relative abundances in each fish tested. ${ }^{40}$ Additionally, $m / z 267.074$ (unidentified) is seen in a higher relative abundance in cod when compared to the other products. Deprotonated anserine $(\mathrm{m} / \mathrm{z} 239.115)$ was qualitatively observed in a higher relative abundance for sockeye salmon, ${ }^{39}$ while a higher relative abundance of deprotonated xanthine $(\mathrm{m} / \mathrm{z}$ 151.025) was observed in halibut. Moreover, a qualitatively higher relative abundance of the chlorine adduct of hexose $(\mathrm{m} / \mathrm{z} 215.032)$ was detected in Atlantic salmon, a farm-raised fish, when compared to wild-caught sockeye salmon, which could be due to their habitats and eating habits.

We then used Lasso to create a five-class model for the fish types analyzed (395 mass spectra obtained for the 45 samples) using LOOCV, yielding $84 \%$ overall accuracy per sample (Figure 3b). The confusion matrix with recall values for each fish type is provided in Supplemental Table 4. Notably, the highest recall was achieved for cod and halibut, which are the most commonly substituted fish meat products as cod loin is often substituted for halibut. ${ }^{731}$ Larger confusion was seen when classifying the farm-raised Atlantic salmon and wild-caught sockeye salmon, which is expected as they are the same fish species and commonly substituted with each other and trout. ${ }^{7}$,

${ }^{31}$ The predictive features selected included deprotonated taurine $(\mathrm{m} / \mathrm{z}, 124.006)$, the chlorine adduct of methyluric acid $(\mathrm{m} / \mathrm{z} 217.011)$, and deprotonated xanthine $(\mathrm{m} / \mathrm{z}$ 151.025) and reflected the trends in relative ion abundances seen in the molecular profiles. While a five-class classifier was built to include the five fish types analyzed, a twoclass and three-class classifier built using LOOCV were also explored for fish that are more commonly substituted in fraudulent activities. For example, a two-class classifier was built to distinguish halibut and cod, which are visually very similar and often substituted in meat fraud crimes, yielding 100\% accuracy with 229 mass spectra acquired from 26 samples (Supplemental Table 5). A three-class classifier was also built to distinguish steelhead 
trout, sockeye salmon, Atlantic salmon, which are also visually similar and commonly substituted in meat fraud crimes. For this classifier, an overall accuracy of $90 \%$ was achieved (352 mass spectra and 40 samples) (Supplemental Table 5). Overall, the classifiers developed here for fish identification demonstrate the potential of the MasSpec Pen for identification of fish type and the investigation of fish fraud.

\section{Authentication of meat products using the MasSpec Pen.}

To evaluate the predictive performance of the classifiers built, we analyzed an independent test set of meat and fish samples using the MasSpec Pen following the same experimental approach. For the grain-fed beef, grass-fed beef, and venison, three biological replicates were analyzed with at least eight analytical replicates for each sample, yielding 71 mass spectra for 9 samples. For the five fish types, four samples were analyzed for each meat type with at least eight analytical replicates per sample, yielding 187 spectra for 21 samples. Using the previous statistical models to predict the meat type for each sample, test set accuracies of $100 \%$ were achieved for the beef model and the beef versus venison model (Figure $\mathbf{2 b}$ and 2c). Similarly, an accuracy of $100 \%$ was achieved for the fish multiclass model (Figure 3b). The accuracies are comparable with what previously reported for LESA-MS, 94.9\% $(\mathrm{n}=50)$ for a training set, and REIMS, $100 \%(\mathrm{n}=20)$ species identification for a training set. ${ }^{26,30}$ Further, the accuracies achieved are comparable with current testing metrics using PCR (96\%-100\%). ${ }^{8-12}$ The performance achieved with the MasSpec Pen in the test set of samples provides evidence the MasSpec Pen in conjunction with lasso is a robust method for analysis of meat products.

\section{Extending the MasSpec Pen use to the analysis of mixed meat samples.}

We next evaluated if the MasSpec Pen could be used to identify adulterated mixed meat samples. To this end, we mixed varying percentages of ground grain-fed beef $(0 \%, 25 \%, 50 \%, 75 \%$, and $100 \%$, in weight), as an adulterant into samples of ground grass-fed beef or ground venison, and analyzed the ground samples using the MasSpec Pen. For the grain-fed beef mixed into grass-fed beef, we analyzed nine $0 \%$ grain-fed beef samples, four $100 \%$ grain-fed beef samples, and six 25\%, 50\%, and 75\% samples. For the grain-fed beef mixed into venison, we analyzed eight $0 \%$ grain-fed beef samples, six $100 \%$ and $25 \%$ grain-fed beef samples, and five $50 \%$ and $75 \%$ samples. When analyzed, each of the ground meat samples had five analytical replicates for each sample. 
The mass spectra obtained from the analysis of the venison samples adulterated with grain-fed beef are shown in Figure 4a. Notably, relative abundances of deprotonated taurine ( $\mathrm{m} / \mathrm{z}$ 124.006), deprotonated malic acid $(\mathrm{m} / \mathrm{z}$ 133.013), and deprotonated carnosine $(\mathrm{m} / \mathrm{z} 225.099)$ were increasingly higher with increasing percentage of adulterant grain-fed beef in the ground venison samples. On the other hand, a decrease in the relative abundances of deprotonated succinic acid $(\mathrm{m} / \mathrm{z}$ 117.018) and deprotonated inosine $(\mathrm{m} / \mathrm{z} 267.074)$ was observed as the percentage of adulterant grain-fed beef increases in the ground venison samples. The changes in the relative abundance of the metabolites agreed with the trends observed in the raw meat samples. We then built statistical classifiers to test if classification of meat samples as adulterated was possible using the metabolic information obtained with the MasSpec Pen. To this end, we trained the Lasso method to identify adulterated and unadulterated meat by including mix samples (amount $>25 \%$ ) into the adulterated class and ground samples $(0 \%$ mixed) in the unadulterated class. Using the training set data of 76 mass spectra and 20 samples, an overall $93 \%$ per spectra accuracy and a $90 \%$ per samples accuracy was achieved (Figure 4b). The features were selected for prediction of the two classes and reflected trends in molecular profiles seen in Figure 4a. For example, deprotonated carnosine, which has been previously found to be present in skeletal muscles of beef, was selected as a predictive feature weighted towards the adulterated with grain-fed beef classification, while deprotonated inosine $(\mathrm{m} / \mathrm{z}, 267.074)$ was selected as a predictive feature weighted towards the unadulterated classification. ${ }^{38-39}$ Within the training set, two unadulterated samples were misclassified as adulterated samples, while no adulterated samples were misclassified. We then tested the classifier on 43 mass spectra acquired from 10 samples, including 7 adulterated samples and 3 unadulterated samples. Overall accuracies of $98 \%$ per mass spectra and $100 \%$ per sample were achieved for the venison mixed samples test set (Figure $\mathbf{4 b}$ ).

The mass spectra obtained from the analysis of the grass-fed beef adulterated with grain-fed beef are shown in Figure 5a. As the amount of grain-fed beef adulterant increased in the samples, the relative abundances of ions such as deprotonated taurine $(\mathrm{m} / \mathrm{z}, 124.006)$, deprotonated malic acid $(\mathrm{m} / \mathrm{z}, 133.013)$, and deprotonated D-erythro-Lgalacto-nonulose $(\mathrm{m} / \mathrm{z} 269.088)$ also increased, while a decrease in the relative abundances of deprotonated succinic acid $(\mathrm{m} / \mathrm{z}$ 117.018) and deprotonated xanthine $(\mathrm{m} / \mathrm{z}$ 151.025) was observed. Similar to the adulterated venison classifier described above, a binary classifier was built for the beef samples in which grain-fed beef was used as an adulterant to grain-fed beef meat. Using a training set of 88 mass spectra and 21 samples, an overall accuracy of 
92\% per mass spectra and 90\% per sample was achieved (Figure 5b). Within the several features selected by the model, including deprotonated malic acid and deprotonated anserine weighted towards the adulterated classification and deprotonated xanthine weighted towards the unadulterated classification. One unadulterated sample was misclassified as adulterated in the training set. When tested on 45 mass spectra acquired from 10 samples in the validation set, 100\% accuracy per mass spectra and per sample was achieved (Figure 5b). Multiple LC-MS methods have previously reported detection limits down to $3 \%$ for various mixed meat samples. ${ }^{13-14}$ Collectively, the results for both classifiers demonstrate feasibility in developing the MasSpec Pen and lasso as a robust method for the authentication of mixed meat samples, although further studies using lower percentages of substituted meat are needed to validate these findings.

In conclusion, in this study we describe the optimization and application of the MasSpec Pen technology for analysis and classification of meat products. We showed that the gentle nature of the MasSpec Pen analysis allows detection of a range of metabolic species directly from fish, beef, and venison without the need of sample digestions or alteration. Several of the metabolic species detected, including deprotonated carnosine, deprotonated xanthine, deprotonated inosine, deprotonated anserine, the chlorine adduct of hexose, and deprotonated taurine have been previously described in meat samples and related to eating habits and other metabolic process in animal skeletal muscle tissues. ${ }^{38-41,43}$ Using statistical classification with the Lasso method, we demonstrate the robustness and high accuracy of the MasSpec Pen in identifying meat types in training (93\% accuracy, $\mathrm{n}=85$ ) and test sets (100\% accuracy, $\mathrm{n}=33$ ). Further, we showed that common meat replacement could items could be identified using our approach, including discrimination of meats commonly used for replacement fraud such as grain-fed versus grass-fed beef ( $100 \%$ accuracy in test set, $n=6)$, and different fish types (100\% accuracy in test set, $n=21)$, with similar performance to what reported with other ambient ionization MS methods and other routine meat testing techniques. ${ }^{8-12,26,30}$ Lastly, we showed feasibility for identification of adulterated mixed meat samples. Although the MasSpec Pen is limited to qualitative molecular evaluation with substantially lower molecular coverage when compared to LC-MS, the MasSpec pen analysis is completed in less than 15 seconds and does not require any sample pre-processing, which is appealing for routine use in testing of meat products. At a minimum, the 15 -second testing time per sample provided by the MasSpec Pen is 240 times faster than LC-MS (considering a total analysis time of 1 hour/sample), and 720 times faster than PCR (considering a total analysis time of 3 hours/sample). 
Further, the ease of use and maneuverability that a handheld device like the MasSpec Pen allows can facilitate implementation and use by users with various levels of expertise. Due to the gentle nature of the analysis, repetitive analysis of different products and regions within the sample of interest can be achieved. Future research would include expanding meat identification classifiers, improving the mixed meat results, and developing methods to quantify the amount of adulterant present in a sample. Furthermore, we will expand our method to other meat products, such as wild fish products and beef products from different countries. Lastly, while a high-performance Orbitrap mass spectrometer was used here for this exploratory study, we are currently exploring integration of the MasSpec Pen with a portable ion trap mass spectrometer for meat analysis to facilitate fieldable use outside of specialized laboratories. Collectively, our study shows compelling evidence that the MasSpec Pen provides a rapid and direct method for investigating meat fraud, allowing for accurate meat identification in less than fifteen seconds, thus providing a powerful alternative technique to traditional meat testing methods.

\section{Acknowledgments}

This work was supported by the Welch Foundation (F-1895-20190330), and the Gordon and Betty Moore Foundation (grant GBMF8049). We thank the Eberlin lab members for helpful discussions and assistance with experiments.

\section{Conflicts of Interest}

J.Z., J.Q.L., and L.S.E. are inventors in US Patent No. 10,643,832 and/or in other patent applications related to the MasSpec Pen Technology licensed by the University of Texas to MS Pen Technologies, Inc. J.Z. and L.S.E. are shareholders in MS Pen Technologies, Inc., in which L.S.E. serves as the chief scientific officer. All other authors declare no competing interests. 


\section{References}

1. Johnson, R. Food Fraud and Economically Motivated Adulteration of Food and Food Ingredients; Jan. 10, 2014, 2014; pp 1-40.

2. $\quad$ Black, C.; Chevallier, O. P.; Elliott, C. T., The current and potential applications of Ambient Mass Spectrometry in detecting food fraud. Trac-Trend Anal Chem 2016, 82, 268-278.

3. Commission, E. Q\&A on Horsemeat.

"https://ec.europa.eu/food/safety/official_controls/food_fraud/horse_meat/.

4. Equine DNA and Mislabeling of Processed Beef Investigation. Itreland's Department of Agriculture, F. a. t. M., Ed. March 2013.

5. Committee on the Environment, P. H. a. F. S. d. r., on the food crisis, fraud in the food chain and the control thereof. Parliament, E., Ed. 2013.

6. $\quad$ Abbas, O.; Zadravec, M.; Baeten, V.; Mikus, T.; Lesic, T.; Vulic, A.; Prpic, J.; Jemersic, L.; Pleadin, J., Analytical methods used for the authentication of food of animal origin. Food Chemistry 2018, 246, 6-17.

7. Pardo, M. A. J., Elisa; Perez-Villarreal, Begona, Misdescription incidents in seafood sector. Food Control 2016, 62, 277-282.

8. Cavin, C.; Cottenet, G.; Cooper, K. M.; Zbinden, P., Meat Vulnerabilities to Economic Food Adulteration Require New Analytical Solutions. Chimia 2018, 72 (10), 697-703.

9. Fajardo, V.; Gonzalez, I.; Rojas, M.; Garcia, T.; Martin, R., A review of current PCR-based methodologies for the authentication of meats from game animal species. Trends Food Sci Tech 2010, 21 (8), 408-421.

10. Hossain, M. A. M.; Ali, M. E.; Abd Hamid, S. B.; Asing; Mustafa, S.; Desa, M. N. M.; Zaidul, I. S. M., Double Gene Targeting Multiplex Polymerase Chain Reaction-Restriction Fragment Length Polymorphism Assay Discriminates Beef, Buffalo, and Pork Substitution in Frankfurter Products. Journal of Agricultural and Food Chemistry 2016, 64 (32), 6343-6354.

11. Jonker, K. M.; Tilburg, J. J. H. C.; Hagele, G. H.; De Boer, E., Species identification in meat products using real-time PCR. Food Addit Contam A 2008, 25 (5), 527-533.

12. Ballin, N. Z.; Vogensen, F. K.; Karlsson, A. H., Species determination - Can we detect and quantify meat adulteration? Meat Sci 2009, 83 (2), 165-174.

13. von Bargen, C.; Brockmeyer, J.; Humpf, H. U., Meat authentication: a new HPLC-MS/MS based method for the fast and sensitive detection of horse and pork in highly processed food. J Agric Food Chem 2014, 62 (39), 9428-35.

14. Sentandreu, M. A.; Fraser, P. D.; Halket, J.; Patel, R.; Bramley, P. M., A Proteomic-Based Approach for Detection of Chicken in Meat Mixes. J Proteome Res 2010, 9 (7), 3374-3383.

15. Delatour, T.; Racault, L.; Bessaire, T.; Desmarchelier, A., Screening of veterinary drug residues in food by LC-MS/MS. Background and challenges. Food Addit Contam A 2018, 35 (4), 632-645.

16. Leitner, A.; Castro-Rubio, F.; Marina, M. L.; Lindner, W., Identification of marker proteins for the adulteration of meat products with soybean proteins by multidimensional liquid chromatography - Tandem mass spectrometry. J Proteome Res 2006, 5 (9), 2424-2430.

17. Badu-Tawiah, A. K.; Eberlin, L. S.; Ouyang, Z.; Cooks, R. G., Chemical Aspects of the Extractive Methods of Ambient Ionization Mass Spectrometry. Annu Rev Phys Chem 2013, 64, 481-505.

18. Correa, D. N.; Santos, J. M.; Eberlin, L. S.; Eberlin, M. N.; Teunissen, S. F., Forensic Chemistry and Ambient Mass Spectrometry: A Perfect Couple Destined for a Happy Marriage? Analytical Chemistry 2016, 88 (5), 2515-2526.

19. Takats, Z.; Wiseman, J. M.; Gologan, B.; Cooks, R. G., Mass spectrometry sampling under ambient conditions with desorption electrospray ionization. Science 2004, 306 (5695), 471-473.

20. $\quad$ Feider, C. L.; Krieger, A.; DeHoog, R. J.; Eberlin, L. S., Ambient Ionization Mass Spectrometry: Recent Developments and Applications. Analytical Chemistry 2019, 91 (7), 4266-4290.

21. Chen, H. W.; Venter, A.; Cooks, R. G., Extractive electrospray ionization for direct analysis of undiluted urine, milk and other complex mixtures without sample preparation. Chemical Communications 2006, (19), 2042-2044. 
22. Porcari, A. M.; Schwab, N. V.; Alberici, R. M.; Cabral, E. C.; de Moraes, D. R.; Montanher, P. F.; Ferreira, C. R.; Eberlin, M. N.; Visentainer, J. V., Intact triacylglycerol profiles of fats and meats via thermal imprinting easy ambient sonic-spray ionization mass spectrometry. Analytical Methods 2012, 4 (11), 3551-3557.

23. Porcari, A. M.; Fernandes, G. D.; Barrera-Arellano, D.; Eberlin, M. N.; Alberici, R. M., Food quality and authenticity screening via easy ambient sonic-spray ionization mass spectrometry. Analyst 2016, 141 (4), 11721184.

24. Porcari, A. M.; Fernandes, G. D.; Belaz, K. R. A.; Schwab, N. V.; Santos, V. G.; Alberici, R. M.; Gromova, V. A.; Eberlin, M. N.; Lebedev, A. T.; Tata, A., High throughput MS techniques for caviar lipidomics. Analytical Methods 2014, 6 (8), 2436-2443.

25. Villagra, E.; Santos, L. S.; Vaz, B. G.; Eberlin, M. N.; Laurie, V. F., Varietal discrimination of Chilean wines by direct injection mass spectrometry analysis combined with multivariate statistics. Food Chem. 2012, 131 (2), 692-697.

26. Montowska, M.; Alexander, M. R.; Tucker, G. A.; Barrett, D. A., Rapid detection of peptide markers for authentication purposes in raw and cooked meat using ambient liquid extraction surface analysis mass spectrometry. Anal Chem 2014, 86 (20), 10257-65.

27. Montowska, M.; Alexander, M. R.; Tucker, G. A.; Barrett, D. A., Authentication of processed meat products by peptidomic analysis using rapid ambient mass spectrometry. Food Chemistry 2015, 187, 297-304. 28. Montowska, M.; Rao, W.; Alexander, M. R.; Tucker, G. A.; Barrett, D. A., Tryptic Digestion Coupled with Ambient Desorption Electrospray Ionization and Liquid Extraction Surface Analysis Mass Spectrometry Enabling Identification of Skeletal Muscle Proteins in Mixtures and Distinguishing between Beef, Pork, Horse, Chicken, and Turkey Meat. Analytical Chemistry 2014, 86 (9), 4479-4487.

29. Balog, J.; Szaniszlo, T.; Schaefer, K. C.; Denes, J.; Lopata, A.; Godorhazy, L.; Szalay, D.; Balogh, L.; Sasi-Szabo, L.; Toth, M.; Takats, Z., Identification of Biological Tissues by Rapid Evaporative Ionization Mass Spectrometry. Analytical Chemistry 2010, 82 (17), 7343-7350.

30. Balog, J.; Perenyi, D.; Guallar-Hoyas, C.; Egri, A.; Pringle, S. D.; Stead, S.; Chevallier, O. P.; Elliott, C. T.; Takats, Z., Identification of the Species of Origin for Meat Products by Rapid Evaporative Ionization Mass Spectrometry. J Agric Food Chem 2016, 64 (23), 4793-800.

31. Black, C.; Chevallier, O. P.; Haughey, S. A.; Balog, J.; Stead, S.; Pringle, S. D.; Riina, M. V.; Martucci, F.; Acutis, P. L.; Morris, M.; Nikolopoulos, D. S.; Takats, Z.; Elliott, C. T., A real time metabolomic profiling approach to detecting fish fraud using rapid evaporative ionisation mass spectrometry. Metabolomics 2017, 13 (12).

32. Song, G. S.; Zhang, M. N.; Zhang, Y. Q.; Wang, H. X.; Li, S. Y.; Dai, Z. Y.; Shen, Q., In Situ Method for Real-Time Discriminating Salmon and Rainbow Trout without Sample Preparation Using iKnife and Rapid Evaporative Ionization Mass Spectrometry-Based Lipidomics. Journal of Agricultural and Food Chemistry 2019, 67 (16), 4679-4688.

33. Rigano, F.; Mangraviti, D.; Stead, S.; Martin, N.; Petit, D.; Dugo, P.; Mondello, L., Rapid evaporative ionization mass spectrometry coupled with an electrosurgical knife for the rapid identification of Mediterranean Sea species. Analytical and Bioanalytical Chemistry 2019.

34. Balog, J.; Perenyi, D.; Guallar-Hoyas, C.; Egri, A.; Pringle, S. D.; Stead, S.; Chevallier, O. P.; Elliott, C. T.; Takats, Z., Identification of the Species of Origin for Meat Products by Rapid Evaporative Ionization Mass Spectrometry. Journal of Agricultural and Food Chemistry 2016, 64 (23), 4793-4800.

35. $\quad$ Zhang, J. L.; Rector, J.; Lin, J. Q.; Young, J. H.; Sans, M.; Katta, N.; Giese, N.; Yu, W. D.; Nagi, C.; Suliburk, J.; Liu, J. S.; Bensussan, A.; DeHoog, R. J.; Garza, K. Y.; Ludolph, B.; Sorace, A. G.; Syed, A.; Zahedivash, A.; Milner, T. E.; Eberlin, L. S., Nondestructive tissue analysis for ex vivo and in vivo cancer diagnosis using a handheld mass spectrometry system. Sci Transl Med 2017, 9 (406).

36. Sans, M.; Zhang, J. L.; Lin, J. Q.; Feider, C. L.; Giese, N.; Breen, M. T.; Sebastian, K.; Liu, J. S.; Sood, A. K.; Eberlin, L. S., Performance of the MasSpec Pen for Rapid Diagnosis of Ovarian Cancer. Clin Chem 2019, $65(5), 674-683$.

37. Tibshirani, R., Regression shrinkage and selection via the lasso: a retrospective. J R Stat Soc B 2011, 73, 273-282.

38. Han, Y.; Gao, B.; Zhao, S.; Wang, M.; Jian, L.; Han, L.; Liu, X., Simultaneous Detection of Carnosine and Answerine by UPHPLC-MS/MS and Its Application on Biomarker Analysis for Differentiation or Meat and Bone Meal. Molecules 2019, 24 (2). 
39. Jung, S.; Bae, Y. S.; Kim, H. J.; Jayasena, D. D.; Lee, J. H.; Park, H. B.; Heo, K. N.; Jo, C., Carnosine, anserine, creatine, and inosine 5'-monophosphate contects in breast and thighmeat from 5 lines of Korean native chicken. Poultry Science 2013, 92 (12), 3275-3282.

40. Artegoitia, V. M.; Foote, A. P.; Lewis, R. M.; Freetly, H. C., Metabolomics Profile and Targeted Lipidomics in Multiple Tissues Associated with Feed Efficiency in Beef Steers. Acs Omega 2019, 4 (2), 39733982.

41. Devi, R.; Yadav, S.; Nehra, R.; Yadav, S.; Pundir, C. S., Electrochemical biosensor based on gold coated iron nanoparticles/chitosan composite bound xanthine oxidase for detection of xanthine in fish meat. J Food Eng 2013, 115 (2), 207-214.

42. Agriculture, U. S. D. o.; Service, A. M.; Livestock, P., and Grain Market News, National Monthly Grass Fed Beef Report. Agriculture, U. S. D. o., Ed. USDA Livestock, Poultry, and Grain Market News, $2019 ;$ p 1.

43. Jenny, B. F.; Polan, C. E., Postprandial Blood-Glucose and Insulin in Cows Fed High Grain. J Dairy Sci 1975, $58(4), 512-514$.

44. $\quad$ Eberlin, L. S.; Margulis, K.; Planell-Mendez, I.; Zare, R. N.; Tibshirani, R.; Longacre, T. A.; Jalali, M.;

Norton, J. A.; Poultsides, G. A., Pancreatic Cancer Surgical Resection Margins: Molecular Assessment by Mass Spectrometry Imaging. Plos Med 2016, 13 (8).

45. $\quad$ Eberlin, L. S.; Tibshirani, R. J.; Zhang, J. L.; Longacre, T. A.; Berry, G. J.; Bingham, D. B.; Norton, J. A.; Zare, R. N.; Poultsides, G. A., Molecular assessment of surgical-resection margins of gastric cancer by massspectrometric imaging. P Natl Acad Sci USA 2014, 111 (7), 2436-2441. 


\section{Figures}
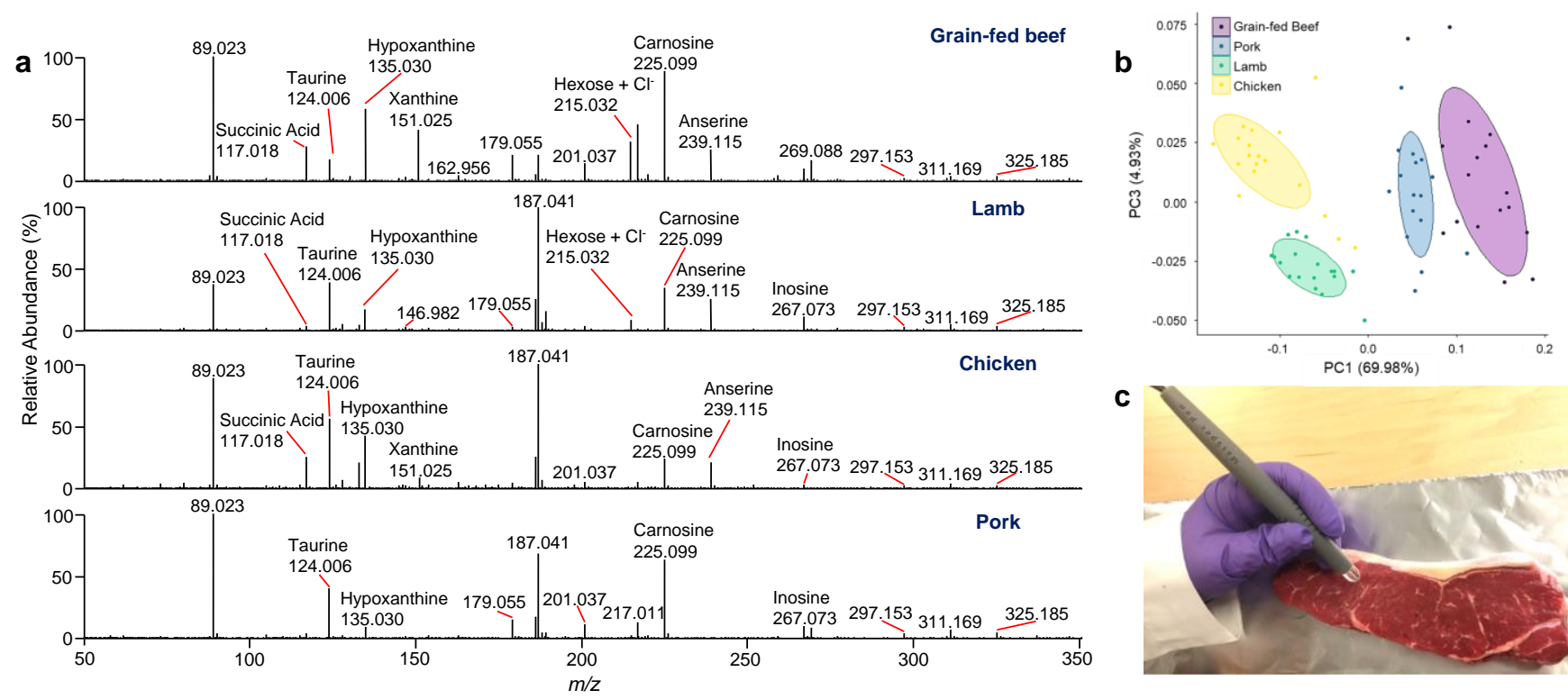

C

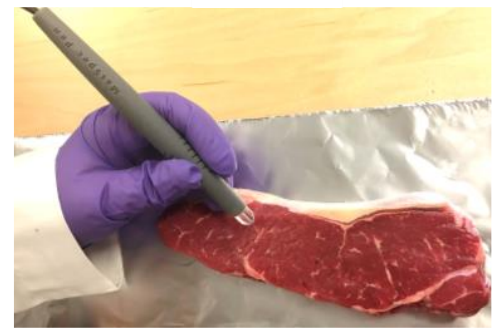

Figure 1. a) Representative negative ion mode MasSpec Pen mass spectra of grain-fed beef, lamb, chicken, and pork. All annotated ions are deprotonated unless stated otherwise. b) PCA plot for the proof of concept study of grain-fed beef, lamb, chicken, and pork. PC1 and PC3 were chosen because they cover the largest variance. c) Picture showing direct MasSpec Pen analysis of a sample of grain-fed beef. 


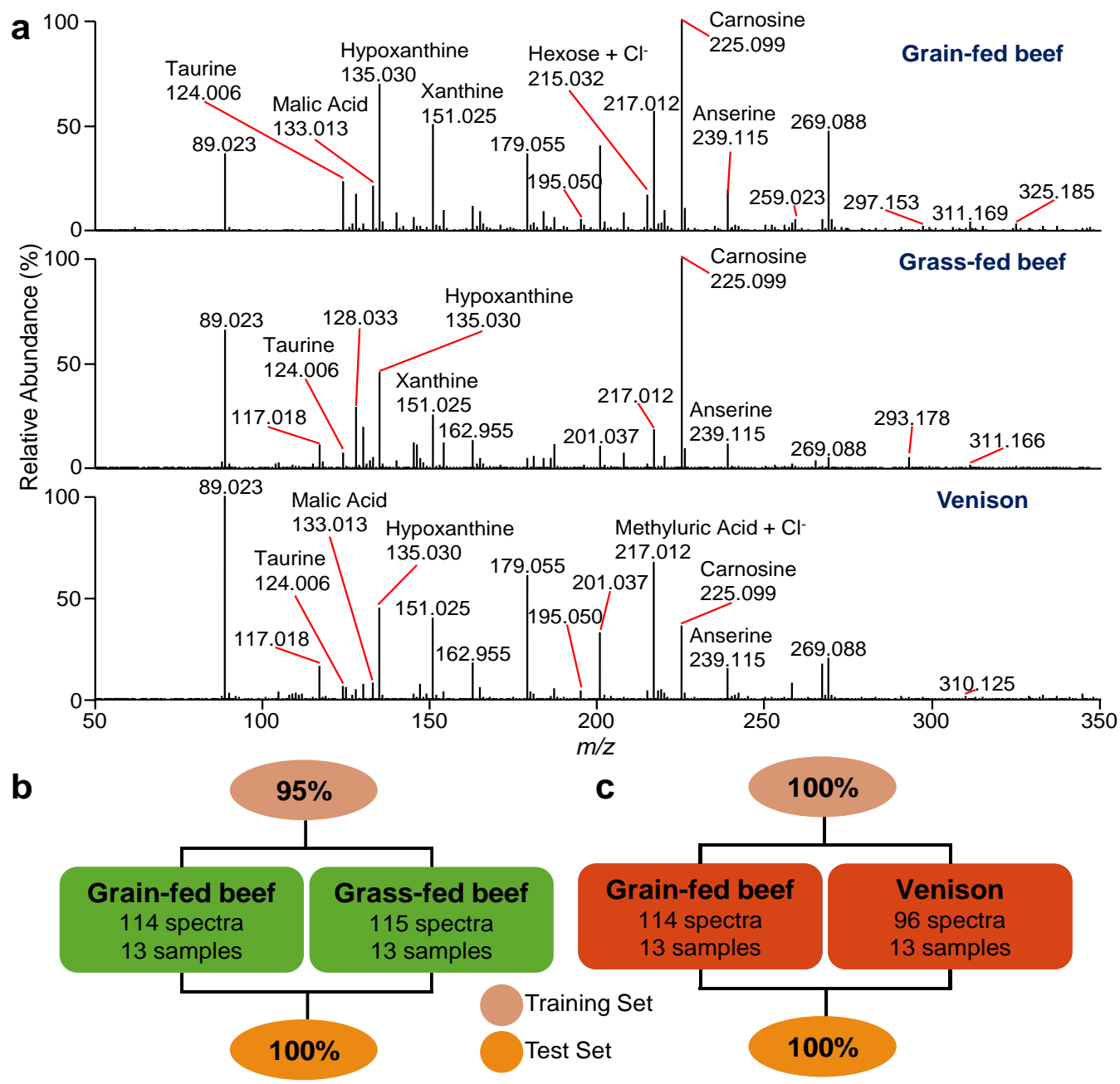

Figure 2. a) Representative negative ion mode MasSpec Pen mass spectra of grain-fed beef, grass-fed beef, and venison. All annotated ions are deprotonated unless stated otherwise. b) Beef training and test set lasso per-sample accuracies. c) Venison and beef training and test set lasso per-sample accuracies. 


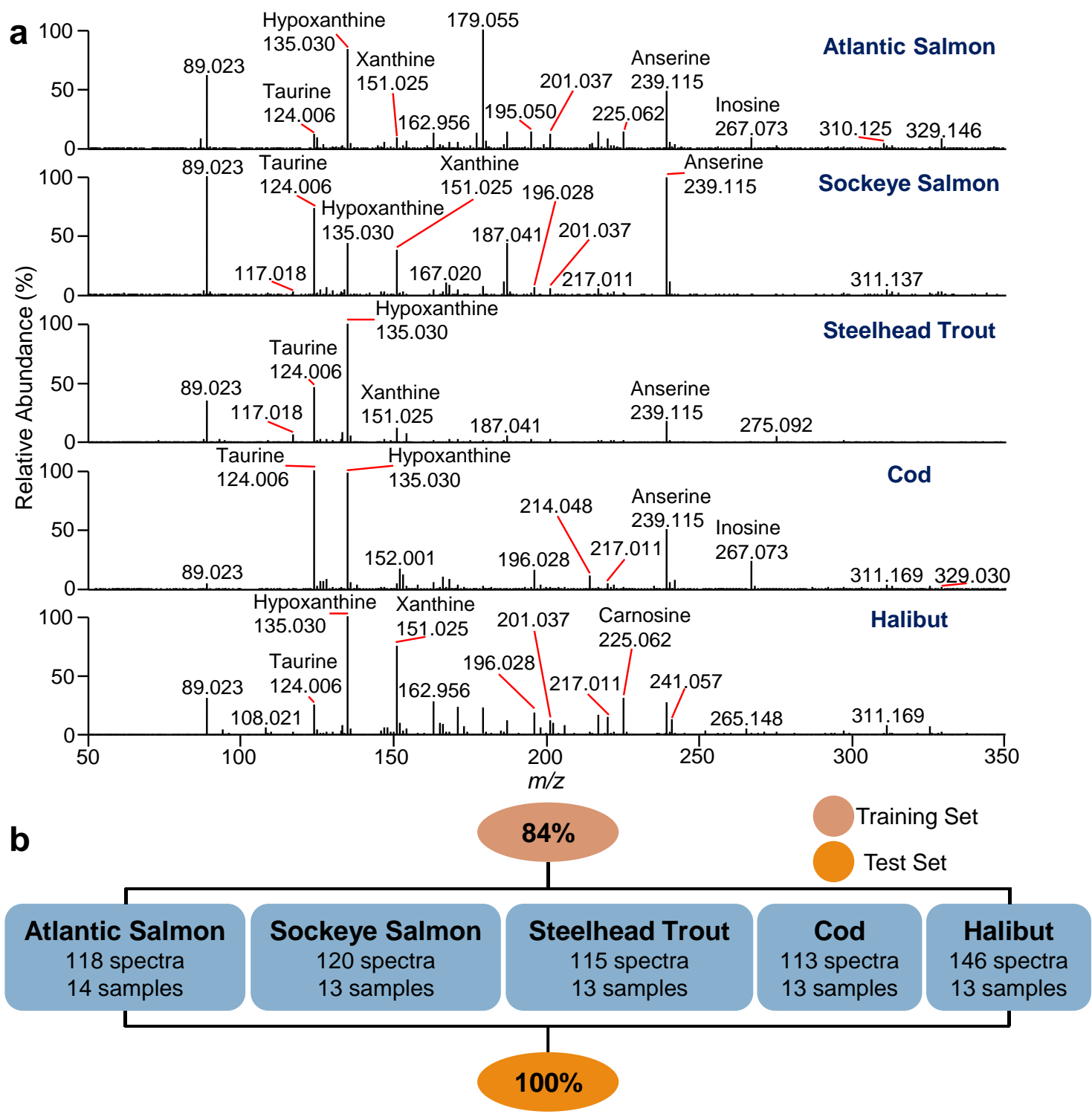

Figure 3. a) Representative negative ion mode MasSpec Pen mass spectra of Atlantic salmon, sockeye salmon, steelhead trout, cod, and halibut. All annotated ions are deprotonated unless stated otherwise. b) Fish training and test set multi-class Lasso per-sample accuracies. 


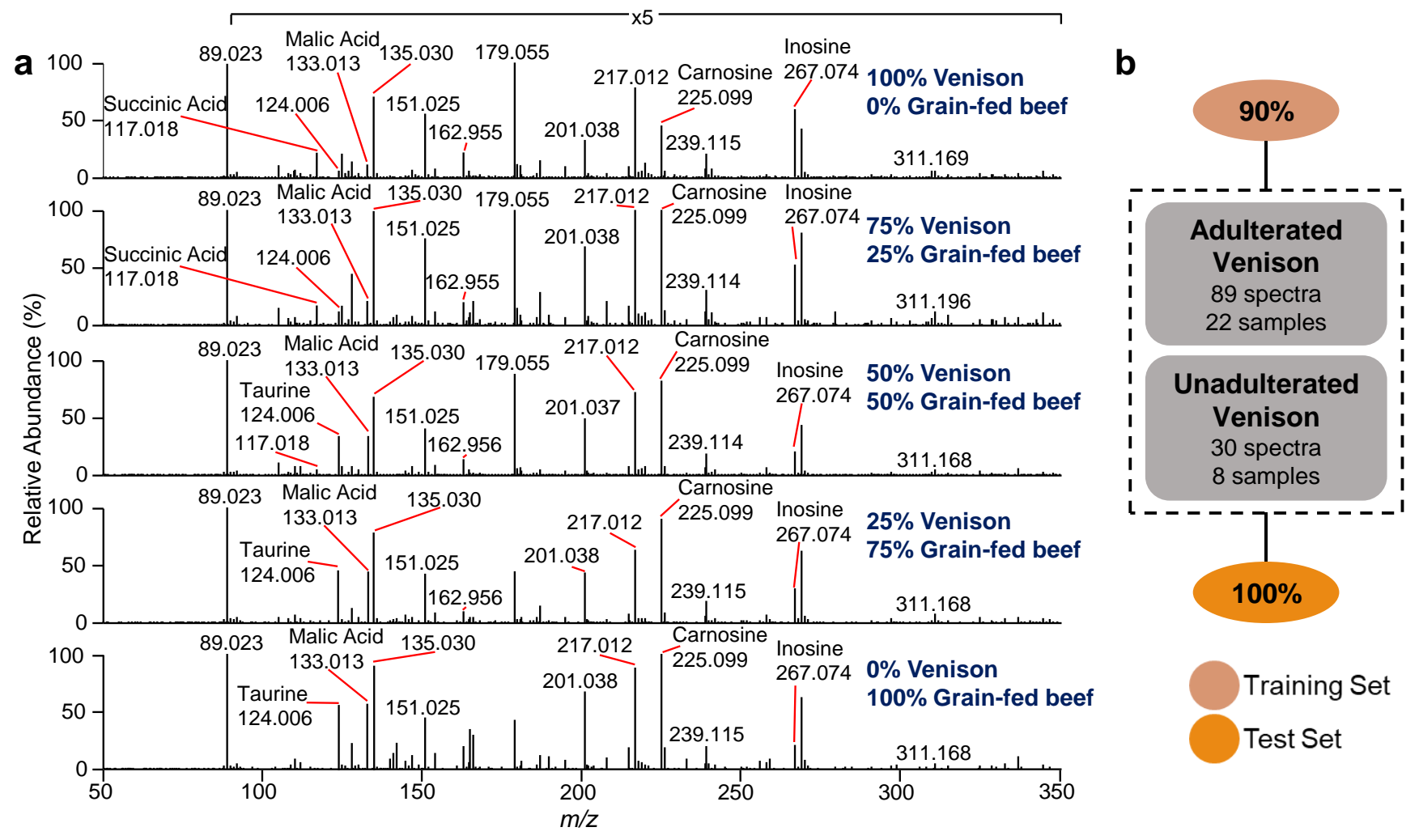

Figure 4. a) Representative negative ion mode MasSpec Pen mass spectra obtained from unadulterated and adulterated ground venison samples. All annotated ions are deprotonated unless stated otherwise. b) Unadulterated and adulterated ground venison samples overall training and test set lasso per-sample accuracies. 


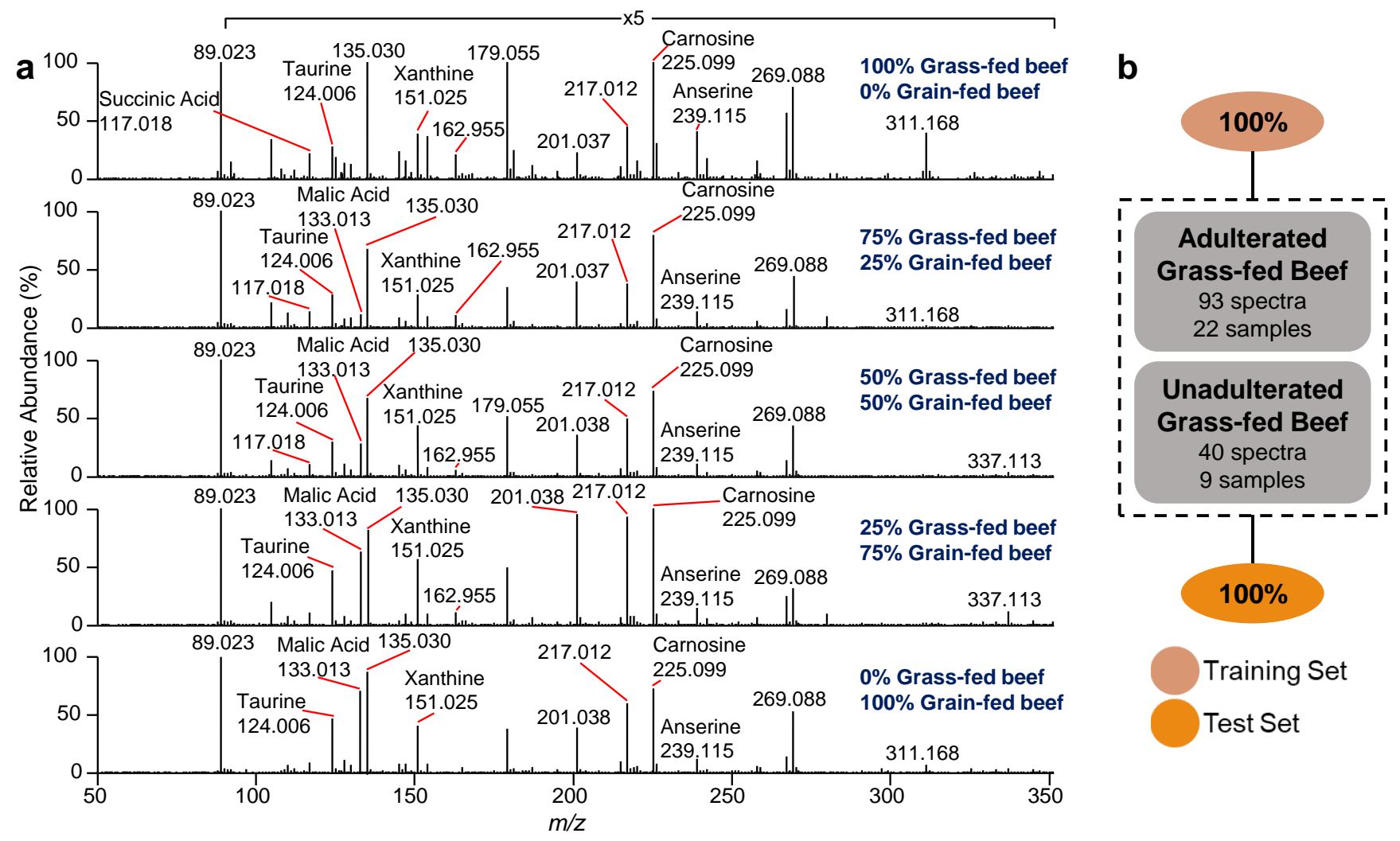

Figure 5. a) Representative negative ion mode MasSpec Pen mass spectra obtained for unadulterated and adulterated ground grass-fed beef samples. All annotated ions are deprotonated unless stated otherwise. b) Unadulterated and adulterated ground grass-fed beef samples overall training and test set lasso per-sample accuracies. 


\section{Supplementary Information}

Rapid Analysis and Authentication of Meat Products using the MasSpec Pen Technology

Abigail N. Gatmaitan ${ }^{1}$, John Q. Lin ${ }^{1}$, Jialing Zhang ${ }^{1}$, and Livia S. Eberlin ${ }^{1} *$

${ }^{1}$ Department of Chemistry, The University of Texas at Austin, Austin, TX, 78712, USA.

* to whom correspondence should be addressed: liviase@utexas.edu 


\section{Supplementary Figures}

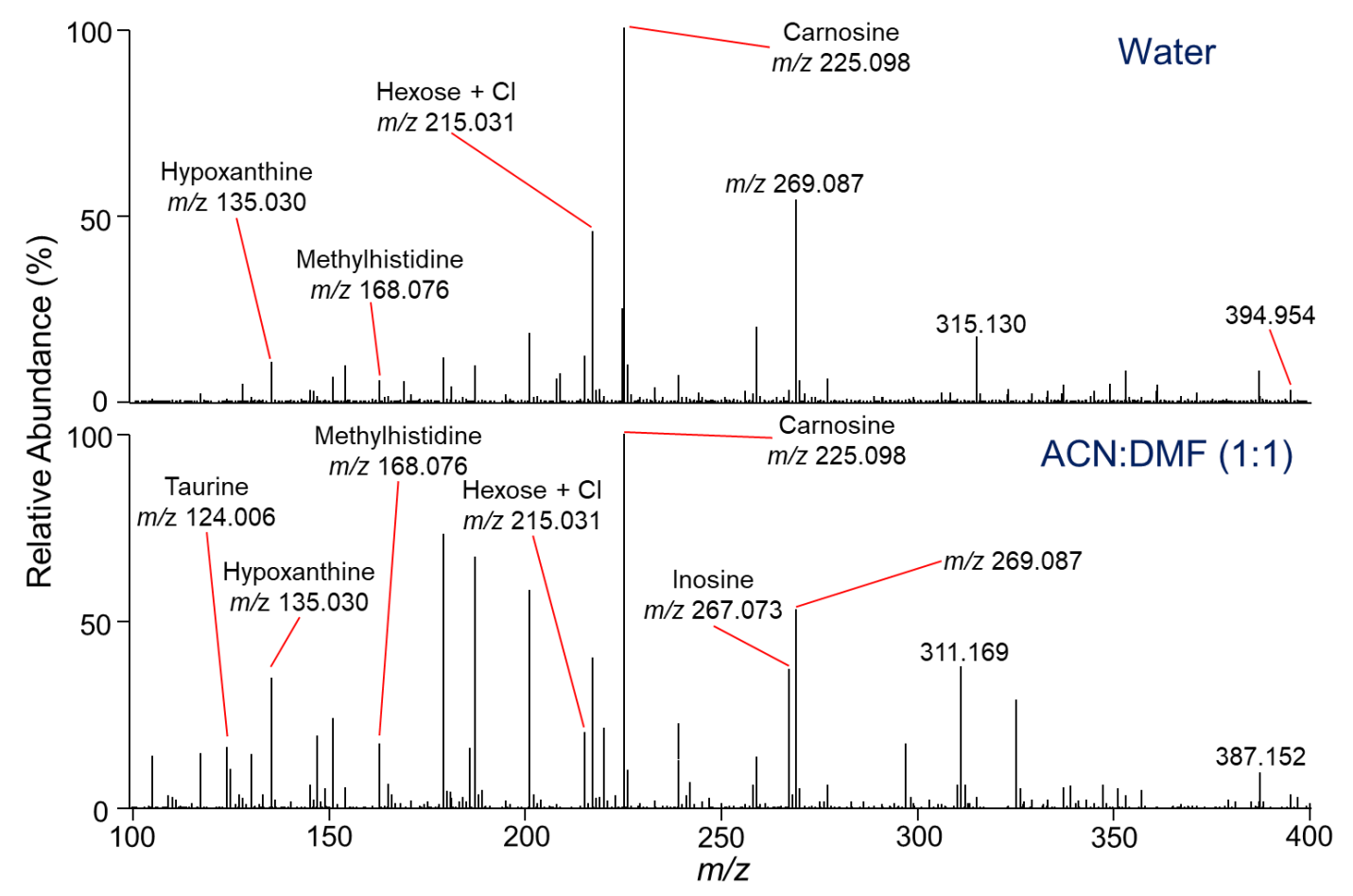

Supplemental Figure 1. Representative mass spectra from a grain-fed beef sample analyzed using water and ACN:DMF (1:1) as the solvent system. All annotated ions are deprotonated unless stated otherwise. 


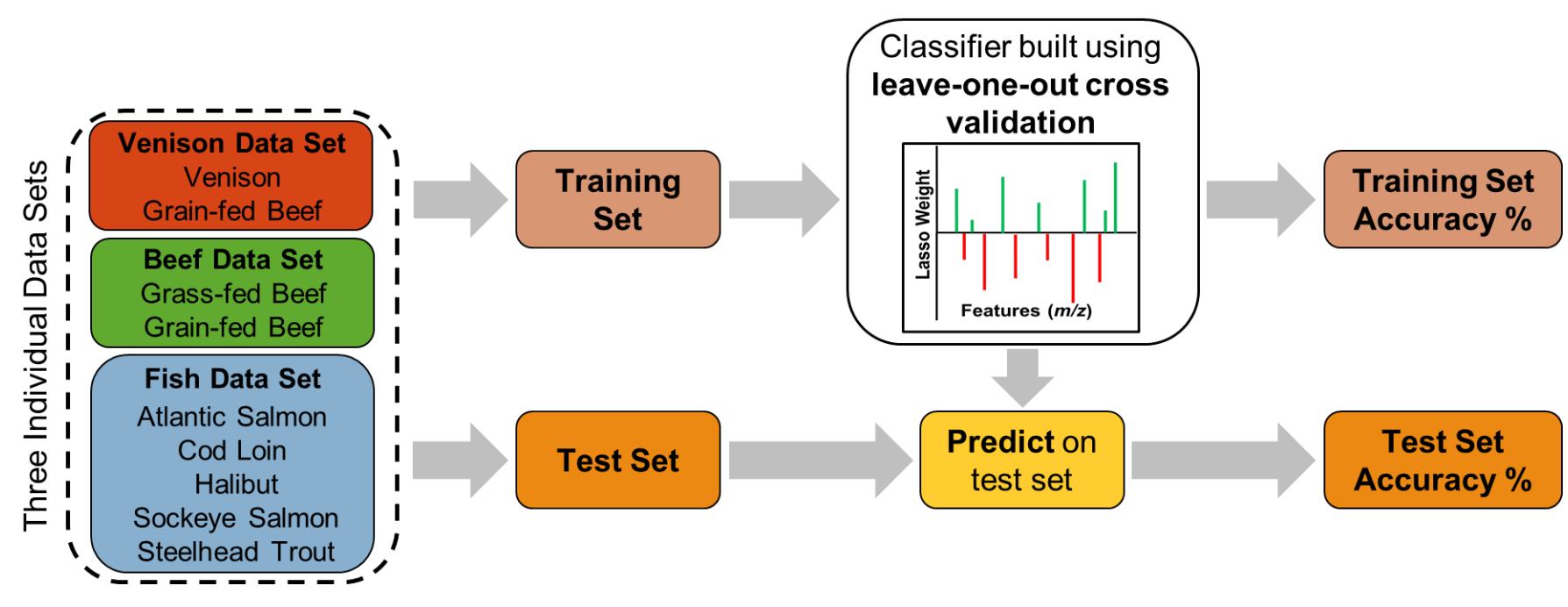

Supplemental Figure 2. Least Absolute Shrinkage and Selector Operator (Lasso) workflow using leave-one-out cross validation (LOO-CV) for creating all lasso models mentioned in this article. 

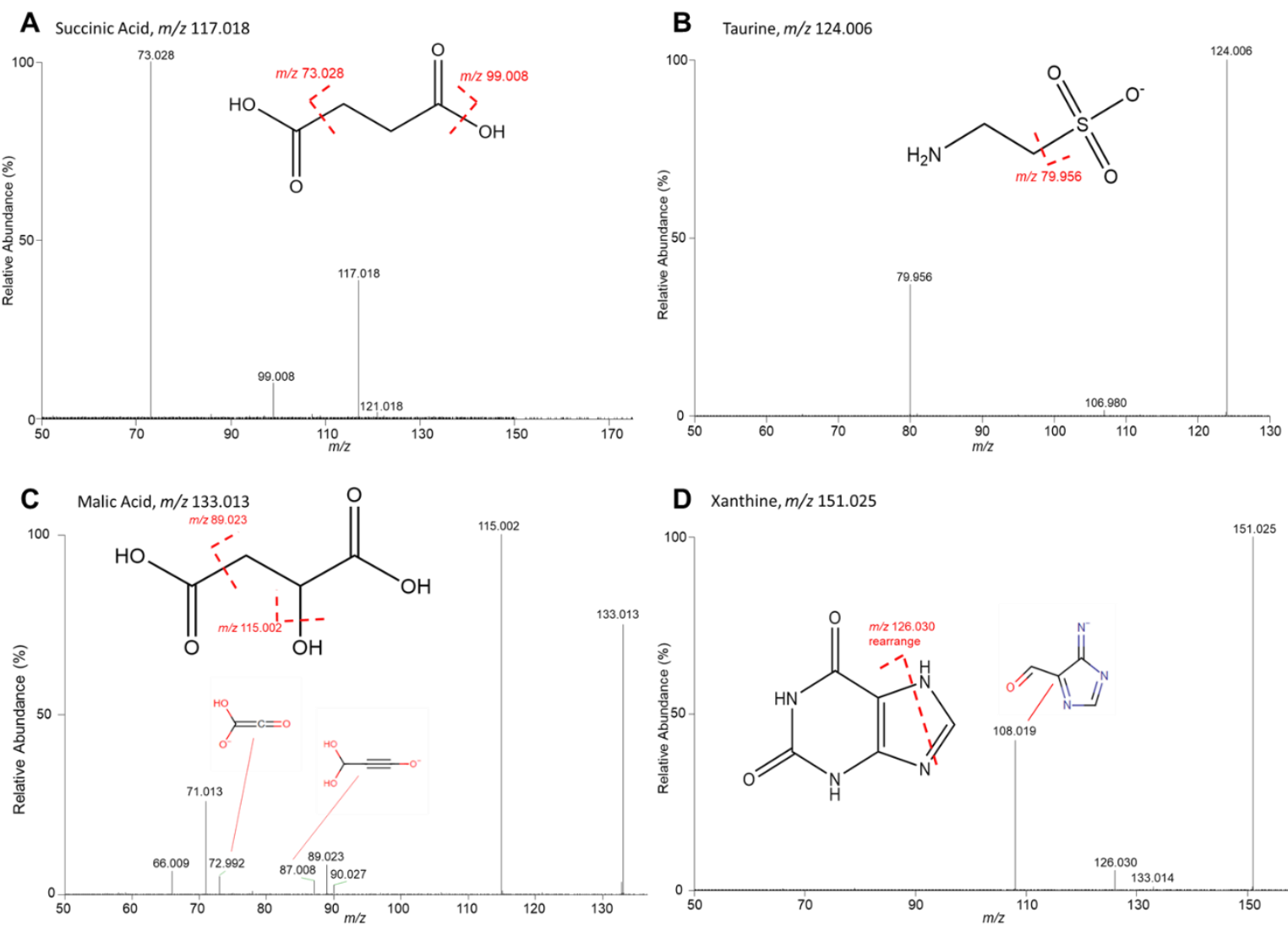

D Xanthine, $m / z 151.025$
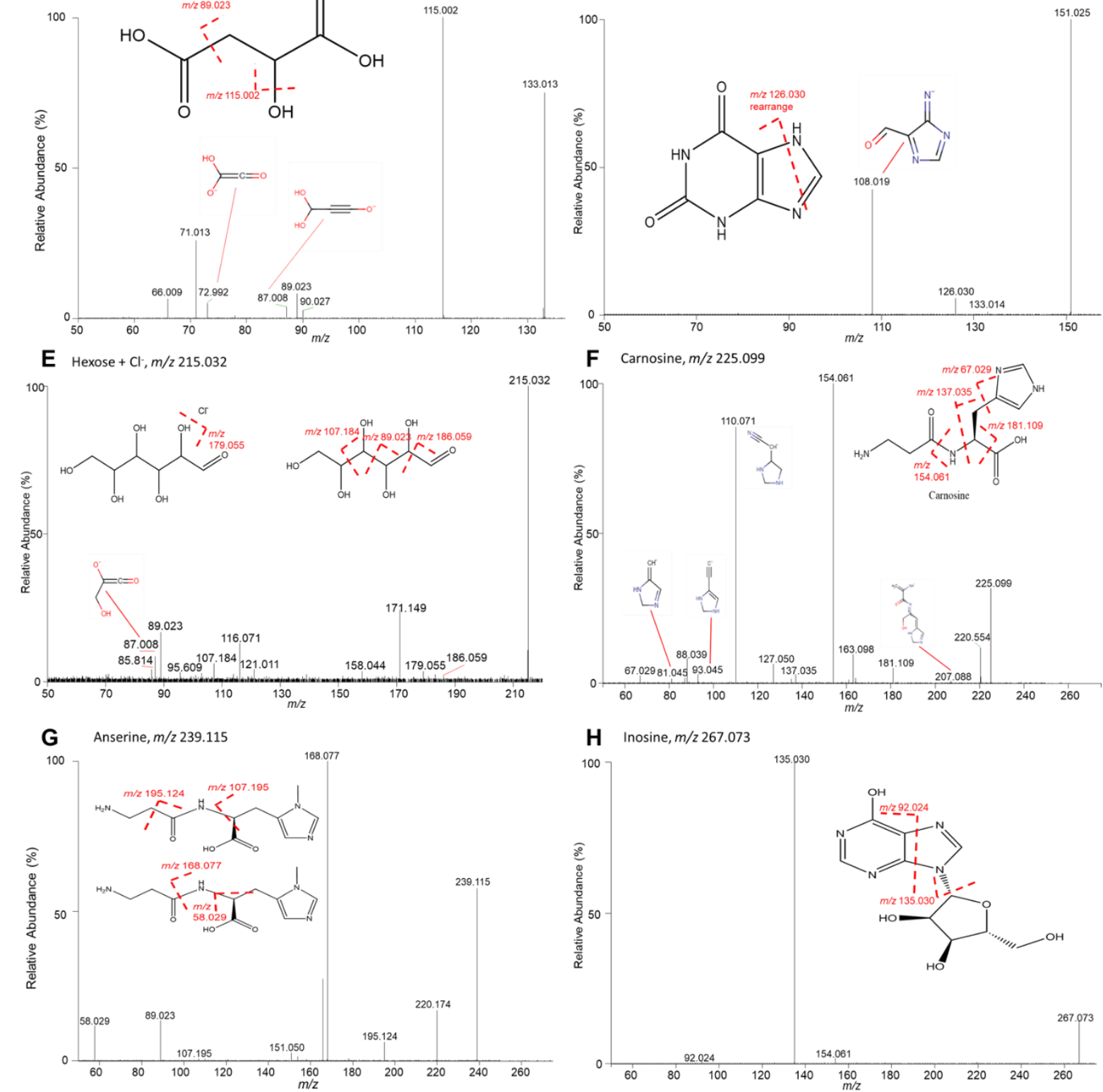

Supplemental Figure 3. Tandem MS/MS of (A) deprotonated succinic acid ( $\mathrm{m} / \mathrm{z}$ 117.018), (B) deprotonated taurine $(\mathrm{m} / \mathrm{z}$ 124.006), (C) deprotonated malic acid $(\mathrm{m} / \mathrm{z}$ 133.013), (D) deprotonated xanthine $(\mathrm{m} / \mathrm{z} 151.025),(\mathbf{E})$ 
chlorine adduct of hexose $\left(\mathrm{m} / \mathrm{z} 215.032,[\mathrm{M}+\mathrm{Cl}]^{-}\right),(\mathbf{F})$ deprotonated carnosine $(\mathrm{m} / \mathrm{z} 225.099),(\mathbf{G})$ deprotonated anserine $(\mathrm{m} / \mathrm{z} 239.115)$, and $(\mathbf{H})$ deprotonated inosine $(\mathrm{m} / \mathrm{z} 267.073)$.

\section{Supplementary Tables}

Supplemental Table 1. Cosine similarity values (A) for tubing lengths $(0.5 \mathrm{~m}, 0.75 \mathrm{~m}, 1.0 \mathrm{~m}$, and $1.5 \mathrm{~m})$ and $(\mathbf{B})$ for extraction times $(3 \mathrm{~s}, 5 \mathrm{~s}$, and $10 \mathrm{~s})$ for the analysis of grain-fed beef using the optimized solvent system, ACN:DMF 1:1. A cosine similarity value of 0 means orthogonal and a value of 1 means identical.

A Tubing Length Cosine Similarity Analysis

\begin{tabular}{cccc}
\hline & $0.75 \mathrm{~m}$ & $1.0 \mathrm{~m}$ & $1.5 \mathrm{~m}$ \\
$0.5 \mathrm{~m}$ & 0.941 & 0.998 & 0.981 \\
$0.75 \mathrm{~m}$ & & 0.955 & 0.981 \\
$1.0 \mathrm{~m}$ & & & 0.987 \\
\hline
\end{tabular}

B

\section{Extraction Time Cosine Similarity} Analysis

\begin{tabular}{ccc}
\hline & $5 \mathrm{~s}$ & $10 \mathrm{~s}$ \\
$3 \mathrm{~s}$ & 0.990 & 0.990 \\
\hline $\mathrm{s}$ & & 0.974 \\
\hline
\end{tabular}


Supplemental Table 2. Training and test set per-sample confusion matrices for grain-fed and grass-fed beef lasso model.

\begin{tabular}{|c|c|c|}
\hline \multirow{2}{*}{ True } & \multicolumn{2}{|c|}{ Predict (Training set) } \\
\hline Grain-fed beef & 10 & Grass-fed beef \\
\hline Grass-fed beef & 1 & 0 \\
\hline True & Predict (Test set) \\
\hline Grain-fed beef & Grass-fed beef \\
\hline Grass-fed beef & 3 & 9 \\
\hline
\end{tabular}


Supplemental Table 3. Training and test set per-sample confusion matrices for grain-fed beef and venison lasso model.

\begin{tabular}{|c|c|c|}
\hline \multirow{2}{*}{ True } & \multicolumn{2}{|c|}{ Predict (Training set) } \\
\hline Grain-fed beef & Grain-fed beef & Venison \\
\hline Venison & 10 & 0 \\
\hline & 0 & 10 \\
\hline True & Predict (Test set) \\
\hline Grain-fed beef & 3 & Venison \\
\hline Venison & 0 & 0 \\
\hline
\end{tabular}


Supplemental Table 4. Training and test set per-sample confusion matrices for multi-class fish lasso model including steelhead trout, cod, halibut, Atlantic salmon, and sockeye salmon.

\begin{tabular}{|l|c|c|c|c|c|}
\hline \multicolumn{1}{|c|}{ True } & \multicolumn{5}{|c|}{ Predict (Training set) } \\
\hline & $\begin{array}{c}\text { Steelhead } \\
\text { Trout }\end{array}$ & Cod & Halibut & $\begin{array}{c}\text { Atlantic } \\
\text { Salmon }\end{array}$ & $\begin{array}{c}\text { Sockeye } \\
\text { Salmon }\end{array}$ \\
\hline $\begin{array}{l}\text { Steelhead } \\
\text { Trout }\end{array}$ & 8 & 0 & 0 & 0 & 1 \\
\hline Cod & 0 & 9 & 0 & 0 & 0 \\
\hline Halibut & 0 & 0 & 9 & 0 & 0 \\
\hline $\begin{array}{l}\text { Atlantic } \\
\text { Salmon }\end{array}$ & 0 & 0 & 0 & 8 & 1 \\
\hline $\begin{array}{l}\text { Sockeye } \\
\text { Salmon }\end{array}$ & 1 & 1 & 1 & 2 & 4 \\
\hline
\end{tabular}

\begin{tabular}{|l|c|c|c|c|c|}
\hline \multicolumn{1}{|c|}{} & \multicolumn{5}{|c|}{ Predict (Test set) } \\
\hline \multicolumn{1}{|c|}{ True } & $\begin{array}{c}\text { Steelhead } \\
\text { Trout }\end{array}$ & Cod & Halibut & $\begin{array}{c}\text { Atlantic } \\
\text { Salmon }\end{array}$ & $\begin{array}{c}\text { Sockeye } \\
\text { Salmon }\end{array}$ \\
\hline $\begin{array}{l}\text { Steelhead } \\
\text { Trout }\end{array}$ & 4 & 0 & 0 & 0 & 0 \\
\hline Cod & 0 & 4 & 0 & 0 & 0 \\
\hline Halibut & 0 & 0 & 4 & 0 & 0 \\
\hline $\begin{array}{l}\text { Atlantic } \\
\text { Salmon }\end{array}$ & 0 & 0 & 0 & 5 & 0 \\
\hline $\begin{array}{l}\text { Sockeye } \\
\text { Salmon }\end{array}$ & 0 & 0 & 0 & 0 & 4 \\
\hline
\end{tabular}


Supplemental Table 5. Leave-one-out cross validation models per-sample confusion matrices for a two-class model of cod and halibut and for a three-class model of steelhead trout, Atlantic salmon, and sockeye salmon.

\begin{tabular}{|l|c|c|}
\hline & \multicolumn{2}{|c|}{ Predict } \\
\hline True & Cod & Halibut \\
\hline Cod & 13 & 0 \\
\hline Halibut & 0 & 13 \\
\hline
\end{tabular}

\begin{tabular}{|l|c|c|c|}
\hline \multicolumn{1}{|c|}{ True } & \multicolumn{3}{|c|}{ Predict } \\
\hline & $\begin{array}{c}\text { Steelhead } \\
\text { Trout }\end{array}$ & $\begin{array}{c}\text { Atlantic } \\
\text { Salmon }\end{array}$ & $\begin{array}{c}\text { Sockeye } \\
\text { Salmon }\end{array}$ \\
\hline $\begin{array}{l}\text { Steelhead } \\
\text { Trout }\end{array}$ & 12 & 0 & 1 \\
\hline $\begin{array}{l}\text { Atlantic } \\
\text { Salmon }\end{array}$ & 0 & 13 & 1 \\
\hline $\begin{array}{l}\text { Sockeye } \\
\text { Salmon }\end{array}$ & 0 & 2 & 11 \\
\hline
\end{tabular}


Supplemental Table 6. Training and test set per-sample confusion matrices for the ground grass-fed beef adulterated with grain-fed beef lasso model.

\begin{tabular}{|c|c|c|}
\hline \multirow[b]{2}{*}{ True } & \multicolumn{2}{|c|}{ Predict (Training set) } \\
\hline & $\begin{array}{l}\text { Unadulterated } \\
\text { Grass-fed Beef } \\
\text { (0\% grain-fed beef) }\end{array}$ & $\begin{array}{c}\text { Adulterated }(25,50 \\
75,100 \% \text { grain-fed } \\
\text { beef })\end{array}$ \\
\hline $\begin{array}{c}\text { Unadulterated } \\
\text { Grass-fed Beef ( } 0 \% \\
\text { grain-fed beef) }\end{array}$ & 5 & 1 \\
\hline \multirow[t]{2}{*}{$\begin{array}{l}\text { Adulterated }(25,50, \\
75,100 \% \text { grain-fed } \\
\text { beef) }\end{array}$} & 1 & 14 \\
\hline & \multicolumn{2}{|c|}{ Predict (Test set) } \\
\hline True & $\begin{array}{l}\text { Unadulterated } \\
\text { Grass-fed Beef } \\
\text { (0\% grain-fed beef) }\end{array}$ & $\begin{array}{c}\text { Adulterated }(25,50 \\
75,100 \% \text { grain-fed } \\
\text { beef })\end{array}$ \\
\hline $\begin{array}{l}\text { Unadulterated } \\
\text { Grass-fed Beef ( } 0 \% \\
\text { grain-fed beef) }\end{array}$ & 3 & 0 \\
\hline $\begin{array}{c}\text { Adulterated }(25,50, \\
75,100 \% \text { grain-fed } \\
\text { beef) }\end{array}$ & 0 & 7 \\
\hline
\end{tabular}


Supplemental Table 7. Training and test set per-sample confusion matrices for the ground venison adulterated with grain-fed beef lasso model.

\begin{tabular}{|c|c|c|}
\hline \multirow[b]{2}{*}{ True } & \multicolumn{2}{|c|}{ Predict (Training set) } \\
\hline & $\begin{array}{l}\text { Unadulterated } \\
\text { Venison ( } 0 \% \text { grain- } \\
\text { fed beef) }\end{array}$ & $\begin{array}{c}\text { Adulterated }(25,50 \\
75,100 \% \text { grain-fed } \\
\text { beef })\end{array}$ \\
\hline $\begin{array}{c}\text { Unadulterated } \\
\text { Venison ( } 0 \% \text { grain- } \\
\text { fed beef) }\end{array}$ & 3 & 2 \\
\hline $\begin{array}{c}\text { Adulterated }(25,50, \\
75,100 \% \text { grain-fed } \\
\text { beef) }\end{array}$ & 0 & 15 \\
\hline \multirow[b]{2}{*}{ True } & \multicolumn{2}{|c|}{ Predict (Test set) } \\
\hline & $\begin{array}{l}\text { Unadulterated } \\
\text { Venison ( } 0 \% \text { grain- } \\
\text { fed beef) }\end{array}$ & $\begin{array}{c}\text { Adulterated }(25,50 \\
75,100 \% \text { grain-fed } \\
\text { beef })\end{array}$ \\
\hline $\begin{array}{c}\text { Unadulterated } \\
\text { Venison ( } 0 \% \text { grain- } \\
\text { fed beef) }\end{array}$ & 3 & 0 \\
\hline $\begin{array}{c}\text { Adulterated }(25,50, \\
75,100 \% \text { grain-fed } \\
\text { beef })\end{array}$ & 0 & 7 \\
\hline
\end{tabular}

